\title{
Justicia jamisonii Jongkind \& Vollesen (Acanthaceae), a new species from Guinée, Côte d'Ivoire and Kenya
}

\author{
Carel C. H. Jongkind ${ }^{1}$ \& Kaj Vollesen ${ }^{2}$
}

Summary. A new species, Justicia jamisonii is described and illustrated. It resembles Rungia paxiana but has a much narrower membranous margin on the inflorescence bracts and the corolla is hairy on the outside. The species has an extraordinary geographical distribution, it is only known from Guinée and Côte d'Ivoire in the west and Kenya in the east, two areas separated by a c. 4,700 km gap. It is described here in Justicia because the genus Rungia will soon be united with the older genus Justicia by the second author.

Key Words. Africa, Rungia, taxonomy.

\section{Introduction}

Three different species of Rungia were collected on recent expeditions around the Nimba Mountains. Two of them were identified as Rungia guineensis Heine and R. paxiana (Lindau) C. B. Clarke. The third one also keys out as $R$. paxiana using the key in Flora of West Tropical Africa (Heine 1963: 429) but the recently collected plant is different and is described here as new.

\section{Taxonomy \\ Justicia jamisonii Jongkind $\mathcal{E}$ Vollesen sp. nov. Species nova Rungiae paxianae (Lindau) C. B. Clarke affinis, sed bracteis inflorescentiae margine translucenti multo angustiore differt. Typus: Guinée, Nimba Moun- tains, Gouan Valley, $850 \mathrm{~m}$ alt., 21 Aug. 2008, Jongkind 8374 (holotypus WAG; isotypus $\mathrm{K}$ ).}

http:/ /www.ipni.org/urn:lsid:ipni.org:names:77116131-1

Herb c. $0.5 \mathrm{~m}$. high. Leaves opposite, entire, petiolate; lamina papery, up to $22 \mathrm{~cm}$ long and $5 \mathrm{~cm}$ wide, gradually narrowing to the petiole, apex acuminate, puberulous on both sides, with $6-9$ pairs of lateral nerves, midrib and lateral nerves more densely hairy. Inflorescence a sessile, axillary spike up to $3 \mathrm{~cm}$ long; bracts and bracteoles $5-7 \times 3-5 \mathrm{~mm}$, uniformly green with a narrow c. $0.5 \mathrm{~mm}$ wide colourless membraneous margin, apiculate, upper half outside with many c. $1.5 \mathrm{~mm}$ long, white to pale brown straight hairs on the surface and along the edge, lower half almost glabrous. Calyx $4-5 \mathrm{~mm}$ long, with 5 gradually narrowing lobes slightly different in length. Corolla 2lipped, lower lip trilobed, white with purple dots on the middle lobe of the lower lip, puberulous on the outside, with 2 pockets of hairs in the mouth on the upper lip, lobes imbricate in bud, tube $3-4 \mathrm{~mm}$ long, infundibuliform, lips c. $3 \mathrm{~mm}$ long; stamens 2, exserted from the corolla tube, filaments $2-3 \mathrm{~mm}$ long, glabrous, anthers $1-1.5 \mathrm{~mm}$ long, with obliquely placed thecae, lower theca tailed at base; ovary hairy, style just exserted from the corolla tube, with hairs on lower half. Fruit glabrous or with a few hairs, 2-seeded, the placenta arising elastically from the base at maturity, c. $16 \mathrm{~mm}$ wide after dehiscence; seeds ellipsoid, strongly compressed, $3 \times 4 \mathrm{~mm}$, glabrous. Fig. 1.

DISTRIBUTION. South-eastern Guinée (Guinée Forestière, Nzérekoré), western Côte d'Ivoire (Danané) and western Kenya.

SPECIMENS EXAMINED. CÔTE D'IVOIRE. Mt Tonkoui, Aké Assi 12933 (P); Mt Tonkoui, 1100 - $1200 \mathrm{~m}$ alt., Boughey GC 18218 (K, WAG). GUINÉE. Nimba Mts, Gouan Valley, $850 \mathrm{~m}$ alt., Jongkind 8374 (holotype WAG; isotype K); Nimba Mts, Zougué Valley, $850 \mathrm{~m}$ alt., Nimba Botanic Team WH 650 (K, WAG); Nimba Mts, Schnell 3566 (P). KENYA. Kakamega Forest, Yala R., Iloro, $1650 \mathrm{~m}$ alt., M. G. Gilbert 6900 (EA, K).

HABITAT. Forest on the slopes of mountains; alt. $800-1650 \mathrm{~m}$.

CONSERVATION STATUS. Owing to the very unusual distribution pattern shown by this species it is impos-

\footnotetext{
Accepted for publication November 2011.

1 Biosystematics Group, Wageningen University, Generaal Foulkesweg 37, 6703 BL Wageningen, the Netherlands. e-mail: Carel.Jongkind@wur.nl

2 Royal Botanic Gardens, Kew, Richmond, Surrey TW9 3AB UK.
} 


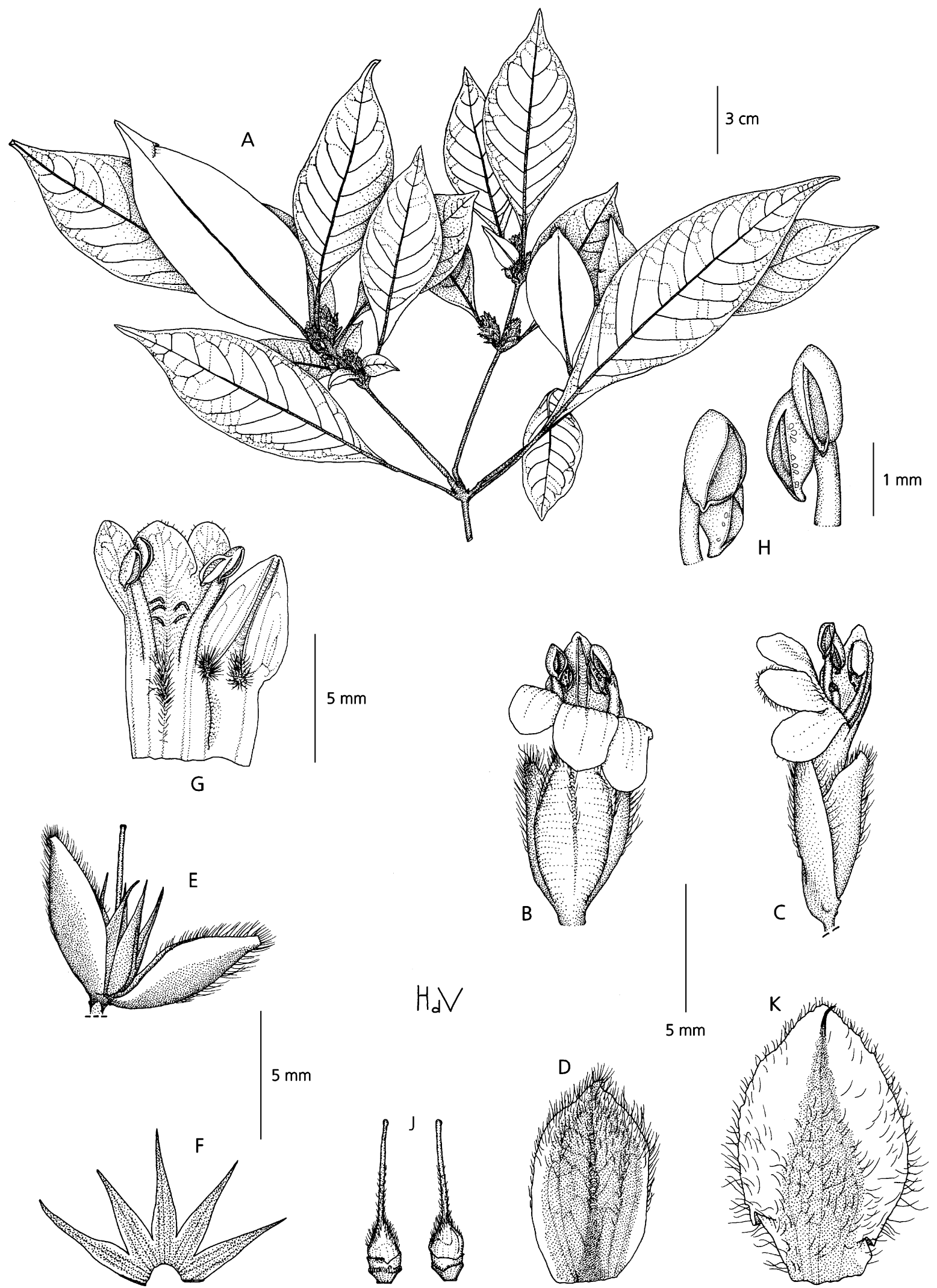

Fig. 1. A - J Justicia jamisonii. A habit; B flower viewed from below; C flower, lateral view; D large frontal bract showing the narrow membraneous margin; E calyx with 2 lateral bracts, the right bract pushed aside to show calyx; $F$ calyx from the outside; $G$ dissected corolla; $\mathrm{H}$ anthers; J ovary and style from 2 sides. K Rungia paxiana large frontal bract for comparison. A - J from Jongkind 8374, $\mathrm{K}$ from Adames 652. DRAWN BY HANS DE VRIES. 
sible currently to give an accurate conservation assessment. Therefore we treat it as Data Deficient (DD) following the IUCN (2001) categories. However, it is certainly not a common species.

ETYMOLOGY. This species is named after Jamison Suter. Without his continuous support over several expeditions in Guinée and Liberia, we would not have been able to undertake most of our fieldwork and the type material of this new species would not have been collected.

NOTES. The leaves of Justicia jamisonii and of Rungia paxiana look much alike and the size of the inflorescences is similar, but the bracts are smaller $(5-7 \mathrm{~mm}$ long vs $8-10 \mathrm{~mm}$ in $R$. paxiana) and the membranous margin of the bracts of the new species are c. $0.5 \mathrm{~mm}$ wide while these of $R$. paxiana are $2-3 \mathrm{~mm}$ wide. Apart from the difference in the bracts, the new species also has the corolla hairy on the outside while it is glabrous in $R$. paxiana. Two of the earlier collected specimens of this new species had been identified as $R$. paxiana and Schnell 3566 from western Africa is cited under this species in the Flora of West Tropical Africa (Heine 1963).

The geographical distribution of the new species was considerably enlarged to the east when the type specimen was shown at Kew to the second author. He recognised it as being the same species as an unidentified Justicia specimen from Kenya in K. The locations in the west and east are separated by a c. 4,700 km gap. It is not the only species found on the Nimba Mountains and nearby highlands and then again far to the east in other forests often at higher elevation, but in these other cases the gap is only $800-1800 \mathrm{~km}$ wide. Examples of such species are Epistemma assianum D. V. Field \& J. B. Hall, Marsdenia exellii C. Norman, Justicia guineensis (Heine) W. D. Hawth., Dorstenia astyanactis Aké Assi and Erica silvatica (Engl.) Beentje. Within Acanthaceae there are other examples of species disjunct between West and East Africa. Satanocrater fellatensis Schweinf. occurs in Guinée and the border regions between Sudan and NW Ethiopia, Crossandra massaica Mildbr. occurs in one locality in Ghana and is widespread in East Africa from Ethiopia to $\mathrm{S}$ Tanzania. Both of these are dry country species.

In the West, three of the five specimens of the new species indicate a preference for forest on medium altitude slopes; altitude data is lacking for the other two specimens. The Kenyan specimen is from somewhat higher altitudes but has a similar ecology.

The new species is described here in Justicia because the genus Rungia will soon be united with the older genus Justicia by the second author.

The following specimens of Rungia paxiana were studied from the same area and vegetation: Côte d'Ivoire, Cascades du Mont Tonkoui, $350 \mathrm{~m}$ alt., Bamps 1940 (BR); Guinée, Nimba Mts, Gouan Valley, $800 \mathrm{~m}$ alt., Jongkind 8362 (BR, WAG); Liberia, Nimba Mts, LAMCO HQ Camp, $550 \mathrm{~m}$ alt., Adames 652 $(\mathrm{K}, \mathrm{P})$.

\section{Acknowledgements}

The first author is grateful to Hans de Vries for preparing the illustrations used in this publication and to Roel Lemmens for the translation of the diagnosis into Latin.

\section{References}

Heine, H. (1963). Acanthaceae. In: F. N. Hepper (ed.), Flora of West Tropical Africa, 2nd ed. part 2: 391 - 432. Crown agents for Overseas Governments and Administrations, London.

IUCN (2001). IUCN Red List Categories and Criteria: Version 3.1. IUCN Species Survival Commission. IUCN, Gland, Switzerland \& Cambridge, UK. 